Note: This is a draft of a paper submitted for publication. Contents of this paper should not be quoted or referred to without permission of the author(s).

To be presented at the 15 th Annual North American Conference on Molecular Beam Epitaxy, University of Maryland, College Park, MD, September 17-20, 1995 and published in Journal of Vacuum Science and Technology

\title{
NEW INSIGHTS INTO THE KINETICS OF THE STRESS-DRIVEN 2D TO 3D TRANSITION
}

K. M. Chen, ${ }^{1}$ D. E. Jesson, ${ }^{1}$ S. J. Pennycook, ${ }^{1}$ T. Thundat, ${ }^{2}$ and R. J. Warmack ${ }^{2}$

${ }^{1}$ Solid State Division, Oak Ridge National Laboratory, Oak Ridge, Tennessee 37831-6031

${ }^{2}$ Health Sciences Research Division, Oak Ridge National Laboratory, Oak Ridge, Tennessee 37831-6123

\begin{abstract}
"The submitted manuscript has been authored by a contractor of the U.S. Government under contract No. DE-ACO5-840R21400. Accordingly, the U.S. Government retains a nonexclusive, royalty-free license to publish or reproduce the published form of this contribution, or allow others to do so, for U.S. Government purposes.
\end{abstract}

\section{SOLID STATE DIVISION}

OAK RIDGE NATIONAL LABORATORY

Managed by

LOCKHEED MARTIN ENERGY SYSTEMS

under

Contract No. DE-AC05-84OR21400

with the

U.S. DEPARTMENT OF ENERGY

Oak Ridge, Tennessee

September 1995 
NEW INSIGHTS INTO THE KINETICS OF THE STRESS-DRIVEN 2D TO 3D TRANSITION

K. M. Chen, D. E. Jesson, S. J. Pennycook, T. Thundat, and R. J. Warmack, Oak Ridge National Laboratory, Oak Ridge, TN 37831-6031.

We have systematically investigated the morphological evolution of $\mathrm{Ge}_{0.5} \mathrm{Si}_{0.5}$ strained films during post-growth annealing. The changes of the surface structure are found to follow the kinetic route of strain relaxation at different stages. A number of interesting features are revealed, which include the existence of an energy barrier to the 2D/3D transition, and a selflimiting effect in the growth kinetics of strained 3D islands. We demonstrate that the annealing approach provides a new way to grow coherent islands with uniform size.

\section{DISCLAIMER}

This report was prepared as an account of work sponsored by an agency of the United States Government. Neither the United States Government nor any agency thereof, nor any of their employees, makes any warranty, express or implied, or assumes any legal liability or responsibility for the accuracy, completeness, or usefulness of any information, apparatus, product, or process disclosed, or represents that its use would not infringe privately owned rights. Reference herein to any specific commercial product, process, or service by trade name, trademark, manufacturer, or otherwise does not necessarily constitute or imply its endorsement, recommendation, or favoring by the United States Government or any agency thereof. The views and opinions of authors expressed herein do not necessarily state or reflect those of the United States Government or any agency thereof. 


\section{INTRODUCTION}

It is well known that flat strained films are inherently unstable against the development of surface undulations, i.e. the formation of three-dimensional (3D) islands. This 2D/3D transition or so called Stranski-Krastanow type growth provides an in situ approach to the fabrication of semiconductor quantum dots ${ }^{1}$ and/or quantum wires. ${ }^{2}$ The success of this method critically relies on our ability to control the size and/or shape of coherent islands, as their optical and electronic properties sensitively depend on these parameters. ${ }^{3}$ Although a remarkably narrow distribution of island sizes has been observed on strained systems such as InAs on GaAs, the mechanism for the observed uniformity in island sizes has not been well understood. Therefore, it is very important to investigate the kinetics and energetics of the stress-driven 2D/3D transition or 3D island growth. Many previous studies have focused on island growth during deposition, in which the high supersaturation could complicate the issues concerning the strain effect on island growth. Here we have carried out a different approach, in which island nucleation and growth were induced by postgrowth annealing. Such studies have revealed a number of surprising features reflecting the interplay between kinetics and energetics during island growth, such as the existence of an energy barrier to 3D island nucleation, multiple kinetic routes for 2D/3D transition, and a self-limiting effect in the growth kinetics of strained 3D islands. ${ }^{4}$

In this report, we present detailed experimental results on the kinetics of the $2 \mathrm{D} / 3 \mathrm{D}$ transition of $\mathrm{Ge}_{0.5} \mathrm{Si}_{0.5}$ strained films during post-growth annealing. The strain relaxation process has been systematically studied and associated with the evolution of surface structure. We demonstrate that the annealing process, with careful control of the transition, is an alternative approach for the growth of coherent islands of uniform size.

\section{EXPERIMENT}

In this study, all samples consist of a $2 \mathrm{~nm}$ thick $\mathrm{Ge}_{0.5} \mathrm{Si}_{0.5}$ strained layer, which was first grown on $\mathrm{Si}(001)$ by low temperature molecular beam epitaxy. The growth was carried out in a 
custom-design MBE system. Substrates are nominally flat Si(100) wafers. A well ordered $(2 \times 1)$ $\mathrm{Si}(001)$ surface was prepared before the $\mathrm{Ge} 0.5 \mathrm{Si}_{0.5}$ thin film was deposited on the surface at $400^{\circ} \mathrm{C}$ with a growth rate of $0.2 \AA / s$. The planar strained films exhibited a streaky $(2 \times 1)$ reconstruction reflection high energy electron diffraction (RHEED) pattern. After the growth terminated, we annealed each sample at different temperatures, while simutaneously monitoring its RHEED pattern to obtain real time information on the surface structure evolution. The $2 \mathrm{D} / 3 \mathrm{D}$ transition was induced by post-growth annealing, and each sample was quenched to room temperature from different stages of the transition. The sample was then taken out of chamber for atomic force microscopy (AFM) measurements, which provided complementary information on the detailed structure of surface morphology. AFM images were acquired using tapping-mode AFM (Digital Inst., Santa Barbara, CA) in a dry, helium-filled glove box.

\section{RESULTS AND DISCUSSION}

Combined RHEED and AFM measurements have revealed the evolution of surface morphology at different annealing temperatures, which provides new insights into the kinetics of island growth. Interestingly, the change of the surface structure or morphology follows a sequence of strain relaxation processes occurring first at the film surface, then at the bulk film and finally at the film-substrate interface. The relaxation process can be loosely divided into the following four stages:

\section{A. INITIAL STRAIN RELAXATION VIA SURFACE RECONSTRUCTION}

Upon the initial annealing at the temperature between 450 and $550^{\circ} \mathrm{C}$, the planar strained film underwent a surface reconstruction change from $(2 \times 1)$ to $(2 \times 8)$, as shown in Figure 1 . This structure change only involves the topmost atomic layers, while the overall surface morphology was still two-dimensional or planar as measured by AFM. Furthermore, the RHEED pattern became much sharper with the annealing, which indicates the improved ordering of the surface atomic structure. 
It has been shown that the $(2 \times n)$ reconstruction on the $(001)$ surface can be caused by external thermal stress or contamination. ${ }^{5}$ Hence we paid strong attention to such possibilities. We annealed a $\mathrm{Si}(001)$ surface as well as a strained surface of $2 \mathrm{~nm}$ thick $\mathrm{Ge}_{0.5} \mathrm{Si}_{0.5}$ layer grown on $\mathrm{Ge}(001)$ with the same annealing condition or procedures. However, no $(2 \times n)$ reconstruction $(n>1)$ was observed. In the former case, the surface involved no misfit strain, while the film surface was subject to $2 \%$ tensile strain in the latter case. The facts indicate the observed $(2 \times 8)$ reconstruction was induced by the $2 \%$ compressive strain in the $\mathrm{Ge}_{0.5} \mathrm{Si}_{0.5} / \mathrm{Si}(001)$ film, rather than contamination or external thermal stress.

Recent STM measurements have shown that the $(2 \times n)$ surface of a strained $\mathrm{Ge}_{\mathrm{x}} \mathrm{Si}_{1-\mathrm{x}}$ film actually consists of missing dimer rows per every $n$ surface dimer rows. ${ }^{6.7}$ The rebonding of the second-layer atoms in the missing dimer rows provides a large tensile stress to cancel the compressive stress of the strained film, as well as the anisotropy stress arising from the $2 \times 1$ dimer reconstruction of the surface. ${ }^{8}$ Hence the surface elastic energy is reduced by the formation of the rebonded missing dimers in the compressively strained $\mathrm{Ge}_{0.5} \mathrm{Si}_{0.5}$ films. Strain relaxation therefore takes place first on the film surface via surface atomic reconstruction, i. e. the formation of periodic missing dimer rows.

\section{B. ELASTIC RELAXATION VIA 3D ISLAND NUCLEATION}

Though the surface stress is relieved significantly through the first stage, the misfit stress in the bulk film is still large, which thus can induce the next stage of strain relaxation via the $2 \mathrm{D}$ to $3 \mathrm{D}$ transition or the formation of 3D islands, as shown in Fig.2 and Fig.3. Energetically, the 3D island morphology allows the elastic deformation or relaxation on a macroscopic scale which can efficiently relieve the large misfit stress stored in the bulk film. If the film is defect-free with no heterogeneous nucleation sites for misfit dislocation, the energy barrier for dislocation nucleation is large. Consequently, if the formation of 3D structure is kinetically accessible, then strain relaxation will proceed via 3D islanding before the nucleation of misfit dislocation. Although the energetics of $3 \mathrm{D}$ islanding is well understood, the understanding of the kinetics of $2 \mathrm{D} / 3 \mathrm{D}$ transition is very 
limited. There is still much controversy surrounding the subject of whether an energy barrier exists to the $2 \mathrm{D} / 3 \mathrm{D}$ transition 2.9 and if so, whether the origin of this barrier can be interpreted in terms of the energies of steps or faceted surfaces. ${ }^{10}$ Our study provide answers to these fundamental questions.

It has been well known that a surface with 3D faceted islands displays a spotty and chevronlike RHEED pattern as seen in the fig.2. By real-time monitoring of the appearance of the chevronlike RHEED pattern, it is possible to directly monitor the onset of the $2 \mathrm{D} / 3 \mathrm{D}$ transition during the annealing process. We have measured the transition as a function of temperature, and surprisingly it shows a sharp transition upon annealing at a temperature above $560^{\circ} \mathrm{C}$. Below $560^{\circ} \mathrm{C}$, no transition is observed for the anneal period as long as 2 hours. Such sharp temperature dependence is not expected from the temperature effect on surface diffusion if the rate-limit step in the transition is determined by the mass diffusion. From AFM measurements on the transition samples, we observed a strong temperature dependence of number density of 3D islands. Most interestingly, we revealed that the initial islands do not have well developed facet structure but evolve continuously in lateral island size and (mean) inclination angle $\theta .\{501\}$ type faceting was found to dominate only at the late stage of island growth.

These experimental results indicate that the rate-limiting step in the transition process arises from an energy barrier to the transition, rather than the mass transportation via surface diffusion. However, the energy barrier exists before the discrete $\{501\}$ faceting occurs. To interpret these observations, we have incorporated atomic steps into the kinetic model of the 2D/3D transition, and calculated the island energy as a function of island size and angle 0.4 An energy barrier region is found to exist along the pathway of island growth, even when the island surfaces are not necessarily faceted. We stress that the physical origin of the barrier can be interpreted in terms of positive step (creation) free energy. The energy barrier strongly depend on temperature and misfit strain, which can explain the puzzling experimental observations, such as the observed sharp 2D/3D transition, and the dependence of 3D roughening on the magnitude and sign of the misfit strain. 


\section{FURTHER RELAXATION VIA ISLAND GROWTH}

Additional strain relaxation is achieved by further growth of the islands upon continuous annealing. Considering the unstable $2 \mathrm{D}$ strained film as an adatom reservoir, one can easily see that the reservoir will continuously provide the adatoms for the growth of islands until the epilayer depleted down to the wetting layer. In other words, the islands will continue to grow until the wetting layer is exposed. This scenario was confirmed by our experiments, which additionally revealed a surprising uniformity of the faceted island sizes for anneals just above the transition temperature. However, initially islands were found to have a broad size distribution. This suggest that there exists a self-limiting behavior at later stages of island growth, i.e. the resistance of large islands to further growth. As a result, small islands grow faster than large ones, and can catch up the sizes of the large islands, thus narrowing the overall size distribution. We have proposed a kinetic model to explain this behavior, in which the local stress concentration at island lower edge restricts the rate at which adatoms from the the $2 \mathrm{D}$ reservoir incorporate into $3 \mathrm{D}$ islands via surface diffusion. ${ }^{11}$

A narrow distribution in island sizes is a crucial factor in the fabrication of quantum dots. Our preliminary results demonstrate that the annealing approach can provide a new way to attaining coherent islands with a monodisperse size distribution.

\section{RELAXATION VIA DISLOCATION INTRODUCTION}

Although the formation of 3D islands relieves the strain energy and consequently delay the introduction of misfit dislocation, they also build up a local stress concentration with their growth via adatom diffusion and/or island coarsening. The high stress concentration consequently provides a preferred nucleation site for misfit dislocations at the lower edge of islands. Such relaxation of the misfit strain via dislocation nucleation was found to occur during annealing at a much higher temperature, $680^{\circ} \mathrm{C}$ or above. Fig. 4 shows the coexistence of coherent islands and incoherent islands on the sample annealed at $680^{\circ} \mathrm{C}$ for 10 minutes. The dislocated islands appear irregularly shaped in the image, and with their average sizes around $200 \mathrm{~nm}$ in diameter, and $15 \mathrm{~nm}$ in height. 
The small coherent islands have the average sizes around $35 \mathrm{~nm}$ in diameter and $2 \mathrm{~nm}$ in height. The large difference in island size and shape between coherent and incoherent islands can be easily understood from the thermodynamics of island growth. When the dislocations are introduced into an island, a large amount of misfit strain is relieved, and consequently the chemical potential of the island is reduced. In other words, the incoherent islands are prefered sinks for adatoms than the coherent islands. As a result, the incoherent islands grow much faster that the coherent ones before the adatom reservoir is exhausted, and may even grow at expense of small coherent islands during the late stages of island coarsening.

\section{SUMMARY}

We have systematically studied the surface structure change of $\mathrm{Ge}_{0.5 \mathrm{Si}} 0.5$ strained film in response to the different stage of strain relaxation. Our results provide important new insights into the kinetics of stress-driven 2D/3D transitions which are of general applicablility to all strained epitaxial systems. The post-growth annealing approach can be used to control the 2D/3D transition to attain a uniform size distribution of coherent islands, which may provide a new way to form quantum dots for optoelectronic device applications.

\section{ACKNOWLEDGMENTS}

We thank T. C. Estes, and J. T. Luck for technical assistance. This work was sponsored by the Division of Materials Sciences, U.S. Department of Energy, under contract DE-AC0584OR21400 with Martin Marietta Energy Systems, Inc., and in part by an appointment to the Oak Ridge National Laboratory Postdoctoral Research Program administered by Oak Ridge Institute for Science and Education. 


\section{References}

1.D. Leonard, et al, Appl. Phys. Lett. 63, 3203 (1993); Phys. Rev. B50, 11687 (1994); J.

Vac. Sci. Technol. B12, 1063 (1994).

2. J. Tersoff, and R, M. Tromp, Phys. Rev. Lett. 70, 2782 (1993). J. Tersoff, F. K. Legoues, Phys. Rev. Lett. 72, 3570 (1994); 74, 4962 (1995).

3. V. Bressler-Hill, et al. Phys. Rev. Lett. 74, 3209 (1995).

4. K. M. Chen, D. E. Jesson, S. J. Pennycook, T. Thundat, and R. J. Warmack, Phys. Rev. Lett., submitted.

5. see for example, J. A. Martin, et al. Phys. Rev. Lett. 56, 1936 (1986); K, Kato, et al, Surf. Sci. 194, L87 (1988).

6. R. Butz, and S. Kampers, Appl. Phys. Lett. 61, 1307 (1992).

7. Xun Chen, F. Wu, Z. Zhang, and M. G. Lagally, Phys. Rev. Lett. 73, 850 (1994).

8.J. Tersoff, Phys. Rev. B45, 8833, (1992).

9.D. J. Srolovitz, Acta Metall. 37, 621(1989); B. J. Spencer, P. W. Voorhes and S. H.

Davis, J. Appl. Phys. 73, 4955 (1993).

10.Y. H. Xie et al., Phys. Rev. Lett. 73, 3006 (1994); 74, 4963 (1995).

11. K. M. Chen, D. E. Jesson, S. J. Pennycook, T. Thundat, and R. J. Warmack, Phys. Rev. Lett., submitted. 
Figure Captions

Fig.1, RHEED pattern from the strained Ge0.5Si 0.5 film surface (a) before annealing; and (b) after annealing at $550^{\circ} \mathrm{C}$ for $10 \mathrm{~min}$. The incident electrons in both patterns are parallel to [110] azimuth direction of the (001) surfaces. The additional streaky spots near each integer order spots in the pattern (b) originate from the periodic missing dimer rows of the $(2 \times 8)$ structure.

Fig.2, RHEED pattern from a strained Ge0.5Si0.5 film surface annealed at $600^{\circ} \mathrm{C}$ for 10 minutes. The incident electrons in pattern (a) and (b) are parallel to [110] and [010] azimuth directions, respectively. The additional chevron-like spots in the both patterns indicate the existence of faceted 3D islands on the surfaces.

Fig.3, AFM image of a strained $\mathrm{Ge}_{0.5} \mathrm{Si}_{0.5}$ film which was annealed at $585^{\circ} \mathrm{C}$ for 6 minutes. The scan size is $2 \times 2 \mu \mathrm{m}^{2}$. Note the uniformity of island sizes with their average sizes of around $40 \mathrm{~nm}$ in lateral direction and $5 \mathrm{~nm}$ in height.

Fig.4, AFM image of a strained $\mathrm{Ge}_{0.5} \mathrm{Si}_{0.5}$ film which was annealed at $680^{\circ} \mathrm{C}$ for 10 minutes. The scan size is $5 \times 5 \mu \mathrm{m}^{2}$. The large, irregularly shaped islands are incoherent, while the small islands are still coherent. 


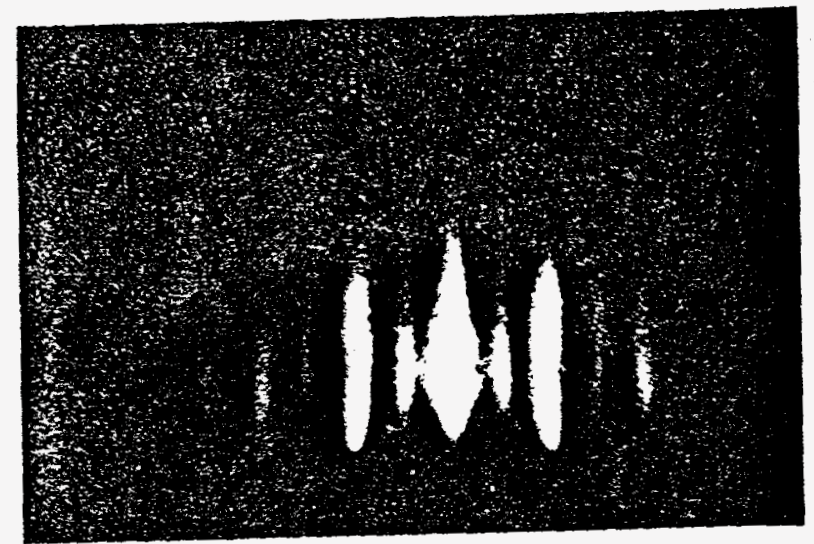

(a)

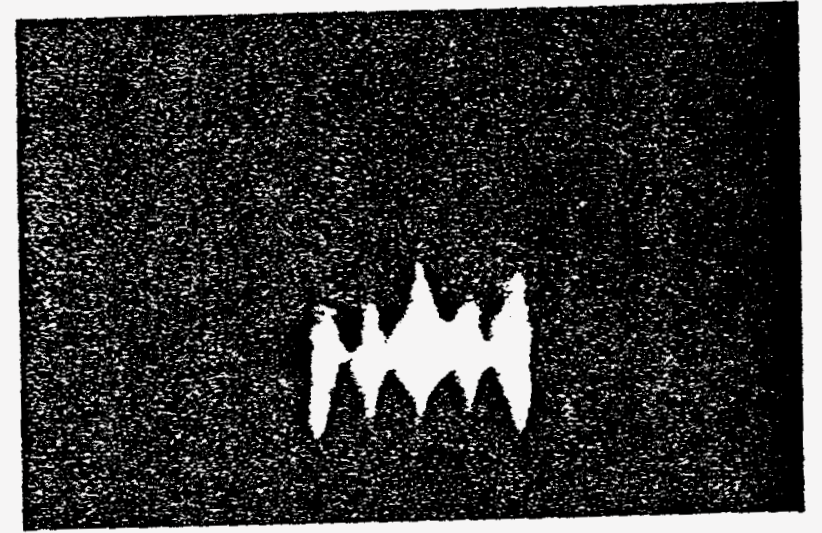

(b)

Fig. 1 K.M.chen etal. 


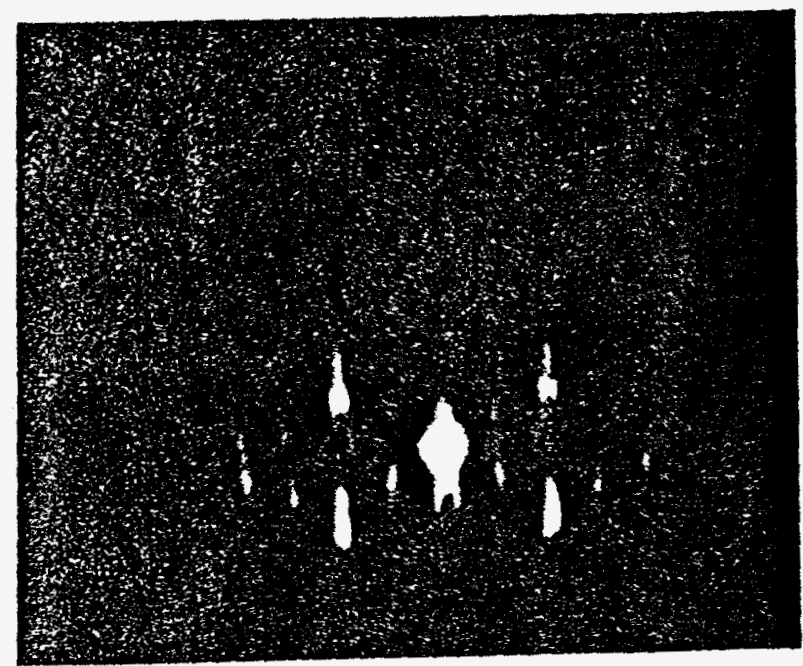

(a)

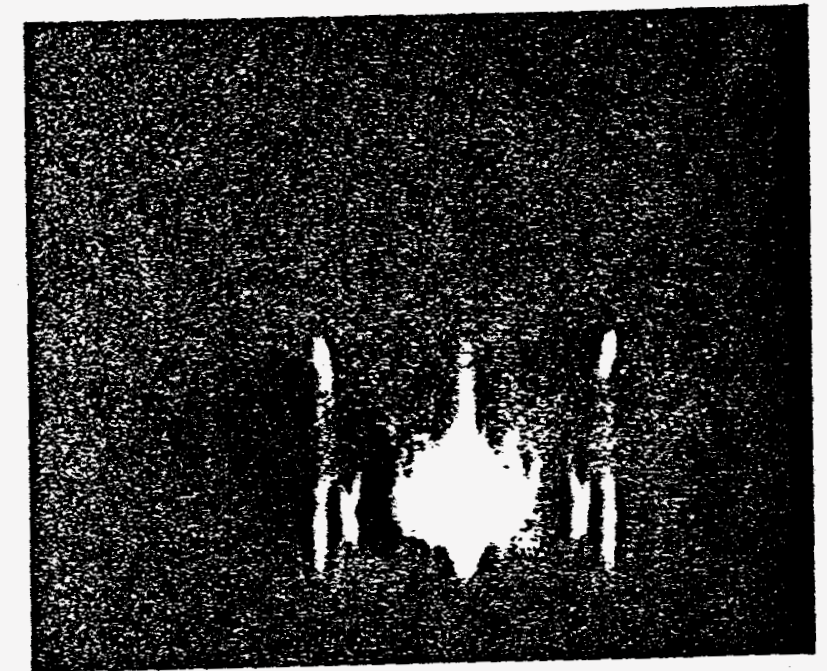

(b)

Fig.2 K.M. Chen et al. 


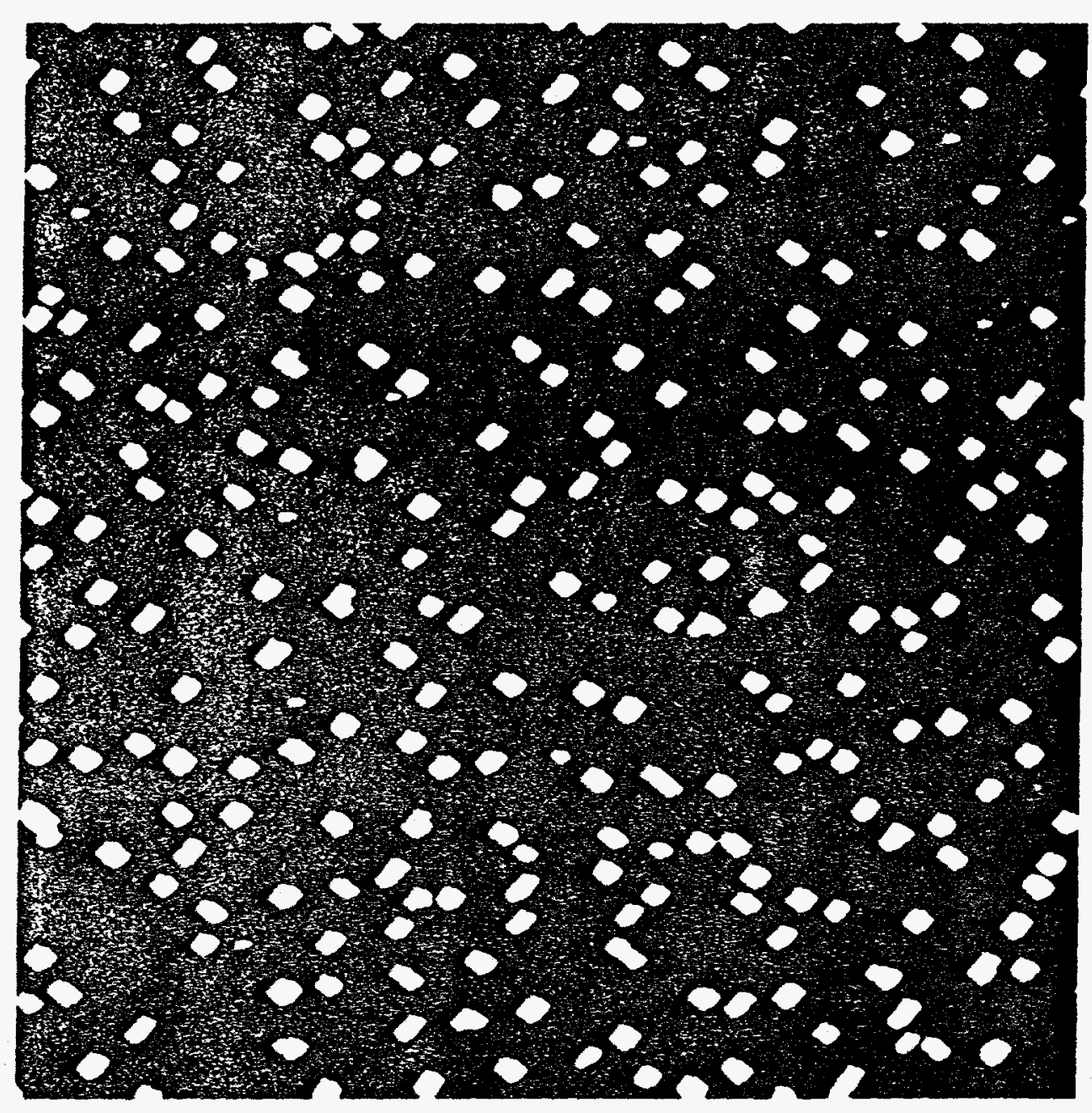

Fig. 3 K.M. Chen et al. 
Fig. 4 K.M. Chen et al 